\title{
ARTE E DELÍRIO: INTERSECÇÃO ENTRE \\ ARTE, POLÍTICA E ECONOMIA NO AMAZONAS
}

\section{Howardinne Queiroz Leão \\ USP}

\section{Resumo}

O presente artigo visa discutir, a partir do livro Arte e delírio - reflexões sobre a cultura no Amazonas, escrito em 1985, pelo Diretório Universitário da Universidade do Amazonas (UA), pilares importantes que geraram uma reflexão acerca do pensamento artístico no Amazonas. 0 livro é composto por cinco ensaios, e cada escritor correspondeu a sua verve: Antônio Paulo Graça discutiu a literatura no Amazonas pela dialética da dependência; Aldísio Filgueiras retratou a relação entre a literatura e poder; Narciso Lobo propôs um diálogo sobre representação de identidade através do filme de Bodanzky, Iracema - uma transa amazônica; Bosco Ladislau promoveu uma reflexão sobre o desenvolvimento da pintura no Amazonas; e finalmente Dori Carvalho, por meio de sua experiência pessoal, encetou uma discussão sobre o teatro na cidade de Manaus. Artistas da geração de oitenta, mobilizados pelas ações da UNE, propõem uma reflexão crítica, sobretudo, aos artistas amazônicos, de como resistir diante de um painel histórico cercado por heranças colonialistas. Ainda, por meio de outros pensadores, pretende-se acrescentar a discussão, na medida do possível, um olhar atual de alguns dos temas levantados pelos autores.

\section{Palavras-chave:}

Cultura amazonense; Dialética da dependência; Teatro em Manaus.

Toda a história é remorso.

Carlos Drummond de Andrade.

Cinco artistas de diferentes segmentos discutem o panorama artístico do Amazonas. O que todos estes ensaios têm em comum? Eles conjugam, cada qual a sua maneira, a relação da arte com fatores econômicos e políticos no Amazonas, desenhando um retrato do pensamento juvenil pós-golpe -

\section{Abstract}

This article aims to discuss, from the book Arte e delírio - reflections on culture in Amazonas, written in 1985, by the University Directory of the University of Amazonas (UA), important pillars that generated a reflection about artistic thought in Amazonas. The book consists of five essays, and each writer corresponded to his own verve: Antônio Paulo Graça discussed literature in Amazonas through the dialectic of dependency; Aldisio Filgueiras portrayed the relationship between literature and power; Narciso Lobo proposed a dialogue on identity representation through Bodanzky's film, Iracema - an Amazonian sex; Bosco Ladislau promoted a reflection on the development of painting in Amazonas; and finally Dori Carvalho, through her personal experience, started a discussion about theater in the city of Manaus. Artists of the eighty generation, mobilized by the actions of the UNE, propose a critical reflection, above all, to Amazonian artists, of how to resist before a historic panel surrounded by colonialist inheritances. Still, through other thinkers, it is intended to add the discussion, as far as possible, a current look at some of the themes raised by the authors.

Keywords:

Amazonian culture; Dependency dialectics; Theater in Manaus.

publicado no ano de abertura política -, ainda aquecido por todos os acontecimentos sociais que mobilizaram o mundo inteiro: a guerra do Vietnã (1959-1975), a exemplar força da juventude francesa no conhecido Maio de 1968, o movimento de organização das ligas camponesas (19551964), a luta armada no continente africano, na década de 1970, e a Revolução Cubana, em 1959, 
apenas para citar alguns exemplos. Não só estes fatos sociais foram catalizadores, mas, também, as diversas manifestações artísticas, projetadas principalmente pela UNE, serviram de inspiração ao movimento juvenil (RIDENTI, 2000).

Sendo assim, as reflexões geradas pelo livro "Arte e delírio" possuem caráter de manifesto, e convocam o leitor a pensar uma transformação social que refletirá, por sua vez, na arte desenvolvida no Amazonas. Com isso, pretendese, em alguma medida, verificar a atualidade desses debates e compreender o pensamento que mobilizou esses artistas a refletirem seu tempo.

A ideia promovida pela UNE - ainda que controversa ${ }^{1}$ -, através do Centro Popular de Cultura (CPC), criado em 1961, no Rio de Janeiro, e interrompido pelo golpe civil-militar em 1964, era articular arte e política, popularizando a arte através de muitas ações artísticas e didáticas. Imbuídos pelas teorias marxistas, acreditavam no papel necessário de elucidar as massas para ativar sua força transformadora e libertária, "improvisavam teatro político em portas de fábricas, sindicatos, grêmios estudantis e na favela, começavam a fazer cinema e lançar discos" (SCHWARZ, 1978, p. 69). Muitos artistas fizeram parte desse movimento, como Glauber Rocha, Vianinha e Ferreira Gullar. Toda a discussão se pautava na "rejeição dos princípios estéticos e da arte como ocupação acadêmica" (GULLAR, 1978, p. 08), visando diminuir a distância entre a arte e o povo.

Contudo, a efervescência artística e intelectual foi duramente interrompida pelo golpe civil-militar no país, e, principalmente, após a implementação do $\mathrm{Al}-5^{2}$, recrudescendo o regime. Perseguições políticas, prisões, exílios, empastelamento de jornais, fechamento de organizações sociais e movimentos estudantis, dentre tantas outras consequências sociais, políticas e culturais. Com efeito, o Partido Comunista $(\mathrm{PC})$, difusor de ideias revolucionárias, já dava rumores a conciliação de classes, esvaindo qualquer possibilidade de revolução, tão aguardada por esses movimentos ascendentes. Schwarz (1978) afirmou que o princípio do Partido Comunista (PC), após aliança com a burguesia, se tornou "combinável com o populismo nacionalista dominante, cuja ideologia original, o trabalhismo, ia cedendo terreno" (p. 63), ou seja, a luta era mantida dentro dos limites econômicos da burguesia.
Curiosamente, é neste período conturbado que surge, com muita força, uma produção intelectual predominantemente esquerdista. Grupos importantes de agitação se mobilizaram, principalmente para discutir uma dramaturgia que colocasse no palco os dilemas brasileiros: o Teatro de Arena, o Teatro Oficina, o Movimento de Cultura Popular (MCP) em Pernambuco e o Grupo Opinião no Rio de Janeiro, foram os principais agentes, este último sendo a "primeira resposta do teatro brasileiro ao golpe militar" (CAMARGO, 1996, p. 101). A herança dessa agitação ainda dominava a juventude:

O interesse pelos problemas políticos, a temática popular, a incorporação da música do morro e do sertão aos espetáculos teatrais, o cinema social e político de hoje têm uma de suas fontes nos movimentos de cultura popular, não apenas pelo efeito das obras, como também pela agitação das ideias que formaram cultural e politicamente os autores novos (GULLAR, 1978, p. 08).

É neste sentido de mudança, que se encaminha o pensamento dos artistas amazonenses, de 1985, sugestionadosporessesacontecimentos, defendiam veementemente o resgate da arte popular ${ }^{3}$. Neste contexto, foi criado pelos universitários do Amazonas o I Festival Universitário de Música, em 1982, na tentativa de reviver os festivais musicais da cidade, e como objetivo principal, estabelecer um espaço de discussão política, além de divulgar os talentos dos artistas locais. Promover este evento no calendário anual da Universidade, e ampliá-lo à sociedade, também era um propósito. De fato, até a publicação de "Arte e delírio", já havia sido feitas três edições do Festival, caracterizando uma atividade de resistência e união do segmento juvenil (GRAÇA, et al., 1985).

O livro, escrito por despontados artistas, então jovens, influenciados pelas ações da União Nacional dos Estudantes (UNE), chama a atenção pelos objetivos que os levaram a tal registro. Destacamos como o primeiro, a necessidade de uma formulação teórica e crítica, que pretendia abandonar o "discurso panfletário", contribuindo à cultura amazonense, bem como a valorização de seus artistas, e na finalidade de conduzir à arte popular, que, segundo a nota de abertura de Antônio Levino (Presidente do Diretório Universitário), é um "elemento essencial na transformação social" (GRAÇA, et al., 1985, p. 2930). Iniciaremos pela explicação desses pontos, para conseguinte, adentrarmos nos ensaios. 
Nos parece que o discurso panfletário frisado, tem a ver com os pontos levantados acima, sobre a frustração de um ideário revolucionário que não ocorreu - pela controversa liderança do PC -, gerando uma reflexão pós golpe, por parte da esquerda, na reavaliação das ações efetivas para alcançar uma arte popular. Boal no ensaio 0 que pensa você da arte de esquerda, de 1968, na ocasião da Primeira Feira Paulista de Opinião, alertava da necessidade de união e reflexão por parte da esquerda, para que a mesma não derrotasse a si mesma (BOAL, 2016). Esperamos destrinchar este tema ao longo do artigo, mesclando com outros pontos elencados pelos autores.

Retomando a necessidade de aumentar a produção deregistrosteóricos, levantados por Levino(GRAÇA, et al., 1985), para contribuir ao Amazonas, e em consequência ao país, faremos um breve regresso a década de 1950, a fim de compreender alguns aspectos sociais que embasam esta questão, pois foi neste decênio que o marasmo cultural, unido ao provincianismo literário da Academia Amazonense de Letras, fundada em 1918, provocou tentativas de mudanças.

Alaúzo (1984) critica o academicismo nos cânones europeus, na arte e na literatura, difundido pela Academia, como padrões já em desuso em outras regiões do país. Da Academia faziam parte figuras de renome da sociedade: Álvaro Maia, Pereira da Silva, Leopoldo Peres, André Araújo, Arthur Reis, Benjamin Lima, entre outros.

A falta de iniciativas públicas, neste período, era outro fator determinante para esse cenário. Djalma Batista foi um dos que teceu críticas ao esfacelamento cultural, cobrando a atuação do Estado para melhorias no segmento. Segundo ele, para recuperar a cidade, traumatizada pós ciclo da borracha, era necessário investir na intelectualidade de seus cidadãos (SOUZA, 1978; AMARAL, 2015). Se de um lado se tinha uma organização inspirada pela Academia Brasileira de Letras, representando o lado conservador, do outro, surgia uma turma de jovens inconformes com a situação, decididos a criar seu próprio movimento de agitação e renovação cultural, O Clube da Madrugada, fundado em 22 de novembro de 1954, por poetas, escritores e intelectuais de toda sorte. O pontapé iniciado por Jorge Tufic Alaúzo, Farias de Carvalho, Alencar e Silva e Antísthenes Pinto, foi dado pela viagem conhecida como "A Caravana", ação responsável por quebrar a barreira geográfica e intercambiar conhecimentos e acontecimentos com outras regiões do país. 0 objetivo do Clube foi modernizar o pensamento sobre a região, através de inúmeras ações artísticas, nas áreas práticas e teóricas, desde exposições, publicações à elaboração de seu Manifesto, influenciados pelo movimento modernista de 1922 (ALA:ZO, 1984).

Encaminhando para a década seguinte, a produção cultural e intelectual se dividiu entre a Academia Amazonense de Letras e o Clube da Madrugada, ainda com certa rivalidade 4 . A publicação de livros era algo raro, pois só havia concretamente dois meios: a Tipografia Fênix, de Sérgio Cardoso, e a Imprensa Oficial do Amazonas, regulada pelo Estado. Posteriormente, surgiram a editora Umberto Calderaro (Jornal A Crítica) e a Casa Madrugada (Clube da Madrugada). O dilema não estava somente nas dificuldades técnicas e na falta de maquinário para produção em massa, mas também na falta de público consumidor de literatura, resultado de um negligente processo histórico cultural (AMARAL, 2015). Referente a isso, o escritor e romancista Márcio Souza (1978), elaborou alguns ensaios de revisionismo crítico sobre a região, afirmando que a Amazônia pouco havia colaborado à cultura brasileira. 0 autor ainda credita características de "pouca memória, estrutura social arbitrária e castradora, eis a vocação aparente de Manaus. Como se faz um artista amazonense? Eis uma pergunta difícil de responder nessa mística afetividade provinciana" (SOUZA, 1978, p. 27). A tônica segue afirmando que o artista é empurrado para fora da cidade, para não ser engolindo pelo provincianismo, pois só assim conseguiria algum reconhecimento no seu trabalho, para depois ser reconhecido na província. Muitos exemplos de artistas amazonenses correram neste sentido: Cláudio Santoro, famoso compositor, o poeta Tenreiro Aranha, o escritor e poeta Thaumaturgo Vaz, entre outros. Souza não está isolado neste pensamento, o leitor verá que essa opinião se faz presente no decorrer dos ensaios, nas devidas proporções.

Diante disso, é que aproximamos a reinvindicação de Levino a esses fatores, ainda atuais, que legitimam a necessidade de maiores publicações e registros teóricos produzidos por artistas e 
intelectuais locais. A pesquisadora Selda Vale da Costa e Ediney Azancoth (2014) sublinham as lacunas existentes na memória artística da cidade por falta de maiores registros, e Souza (1978) complementa sobre muitos dos materiais teóricos serem produzidos por estrangeiros à região. Prosseguiremos aqui propriamente com a discussão dos manifestos de "Arte e delírio", considerado pelos autores como um marco referencial e de grande valor simbólico para o movimento estudantil.

Antônio Paulo Graça ${ }^{5}$ inaugura o debate com o texto Patologia da dependência - introdução ao estudo da literatura do Amazonas. Como o próprio nome sugere, parte de uma análise sobre a dependência da região, presa a uma superestrutura de exploração que vai "da Cabanagem ao Ciclo da Borracha, da dizimação setecentista das nações indígenas à Guerrilha do Araguaia" (GRAÇA, et al., 1985, p. 35). É por essa perspectiva histórica que insere a literatura produzida na região, segundo ele, estreitamente ligada aos processos econômicos, em especial, o projeto contemporâneo da Zona Franca de Manaus ${ }^{6}$. É bem verdade que seu ensaio privilegia um olhar sobre o processo histórico, muito mais do que aprofunda o tema da específico da literatura, mas sua potência consiste justamente em fazer um convite ao interlocutor para olhar a história do Amazonas a contrapelo7, conforme perspectiva a benjaminiana. Gullar (1978) também expressa que a "realidade nacional brasileira, não pode ser entendida se não se leva em conta, por exemplo, o desnível do desenvolvimento econômico entre o Centro-Sul e o resto do País, fato esse que repercute em todos os setores da vida da nação", inclusive nas artes (p. 54).

De fato, a cidade vinha de um abandono generalizado, sintomático em todos os setores, após ter conhecido o período áureo da borracha. Os governos populistas dos anos 1950 e 1960 tentavam repercutir seus feitos, mas era dura a realidade vivenciada, sobretudo, pelas camadas mais pobres que sofriam pela falta de abastecimento de água, energia elétrica, grandes filas para obtenção de mantimentos básicos e alto valor sobre estes itens de consumo, formavam o retrato citadino. A situação também era reivindicada pelas elites locais, que se viram perder da noite para o dia os bens econômicos.
"O marasmo, a miséria, a corrupção, atingem todos os setores [...] Era como se o colonizador houvesse se retirado abruptamente, deixando a colônia saqueada e sem perspectivas no futuro [...]" (SOUZA, 1978, p. 141). Isto é, o golpe civilmilitar não representou truculência maior do que a já experimentada pela população manauara.

Quando veio a implantação da Zona Franca, esta se apresentou como uma grande alternativa de mudança e progresso para tirar a região do caos, mas trazia consigo contradições particulares: a superexploração da mão de obra com salários irrisórios; falta de qualificação necessária e condições adequadas aos seus trabalhadores; submissão a um regime capitalista internacional; expropriação de terras indígenas e terrenos da cidade que passaram ao uso dos militares, construção de estradas e avanço do agronegócio, representando grandes riscos ambientais ${ }^{8}$. Contudo, a elite e a classe política apoiaram e se ludibriaram pelo discurso do progresso, sendo a cidade, ainda hoje, dependente desse sistema econômico, conforme atualiza Sakamoto (2019).

Parte daí a utilização de Graça pelo termo "dialética da dependência" (GRAÇA, et al., 1985, p. 35), conceito esmiuçado por Rui Mauro Marini ${ }^{9}$ (1973), para explicar a:
[...] dependência, entendida como uma relação de subordinação entre nações formalmente independentes, em cujo marco as relações de produção das nações subordinadas são modificadas ou recriadas para assegurar a reprodução ampliada da dependência. A consequência da dependência não pode ser, portanto, nada mais do que maior dependência, e sua superação supõe necessariamente a supressão das relações de produção nela envolvida (MARINI, 2017, p. 327).

Com base na teoria marxista da dependência, Marini (1973) elenca fatores importantes para explicar a dependência dos países da América Latina, e a partir desses pressupostos, a conclusão de que a economia brasileira é subordinada ao imperialismo, sob a lógica do capital estrangeiro, tão bem exemplificada com a Zona Franca. Para Graça, a falta de uma base sólida cultural e social de defesa dos interesses internos surgiu da incapacidade da classe dominante, os herdeiros da borracha, de discernir criticamente este aparelho sistêmico. A injeção econômica também afetou a classe artística, pois muitos passaram a receber algum tipo de apoio para a produção 
de uma arte que não traduzia seu tempo. É este o maior questionamento do autor, ele chama a atenção para o rompimento deste ciclo vicioso, pois o artista, segundo ele, não entende a função de sua condição e exime-se do papel fundamental de questionar.

A falta de uma produção coerente viria então desde a fase cíclica da borracha, pela ausência de uma análise crítica, por parte dos artistas, que em sua maioria só lamentava os efeitos da queda econômica. Diante disso, Graça lança a questão: “E como o intelectual reagiu ao genocídio? De um modo geral, lamentando o fim do ciclo da borracha" (GRAÇA, et al., 1985, p. 40). Ou seja, todos sentiram os abalos econômicos, mas nada se falou sobre o extermínio dos povos autóctones e a exploração do seringueiro. 0 autor alerta para a necessidade de uma auto análise dos artistas para as contradições do seu tempo.

Ele ainda ressalta que esse processo nunca foi vantajoso para a economia local, cujo trabalho pesado era feito sob o comando dos coronéis de barranco, e a última fase (fase do lucro), às empresas estrangeiras na compra da borracha nas casas aviárias. Isto é, a economia de sobrevivência dos barões estava diretamente atrelada ao trabalho semi-escravista. É como explica Marini (2017):

É útil ter presente que a produção capitalista supõe a apropriação direta da força de trabalho, e não apenas dos produtos do trabalho; nesse sentido, a escravidão é um modo de trabalho que se adapta mais ao capital que a servidão, não sendo acidental que as empresas coloniais diretamente conectadas com os centros capitalistas europeus - como as minas de ouro e de prata do México e do Peru, ou as plantações de cana do Brasil - foram assentadas sobre o trabalho escravo (MARINI, 2017, p. 334).

De lá para cá, Graça (1985) sugere que a base do sistema não mudou. O Polo industrial de Manaus é totalmente pautada nas empresas estrangeiras e mais recentemente na presença de empresas do Centro-Sul do país. O lucro maior é destinado a elas, portanto, não é controlado pelo empresariado local. Não há um projeto de fortalecimento do mercado interno, a este resta apenas o comércio e os empregos gerados, ainda com baixo piso salarial. Nem mesmo a matéria prima para a fabricação dos eletroeletrônicos é oriunda da região (SAKAMOTO, 2019).
É incrível perceber a atualidade dos fatos, exemplificados por Graça em 1985 e ainda presentes em 2020, a falta de manutenção do transporte coletivo, com passagens a preços exorbitantes; falta de saneamento básico nos bairros; crescimento desenfreado do mercado imobiliário, avançando sobre áreas verdes, antes preservadas; a deterioração de prédios históricos, pertencentes a memória da cidade, sem qualquer esforço de recuperação; entre muitos outros exemplos. E é ainda atual afirmar que os principais castigados são as classes baixas, periféricas, comunidades da zona rural e as populações indígenas.

Todas as mudanças estruturais pela qual a cidade passou, ainda que planejada nas áreas centrais, não acompanhou o crescimento dos bairros e nem se preparou para a explosão demográfica oriunda da "oferta de empregos" da Zona Franca, estimulando os interioranos a se instalarem na capital (SOUZA, 1977). O principal discurso da Zona Franca é a geração de empregos, que, sob a ameaça do fechamento do Polo Industrial de Manaus, haverá desemprego em massa. Essa é uma característica forte do sistema colonial, que prevalece no sistema capitalista, conforme Memmi (2007, p. 40) expõe: "mas se um dia o econômico é atingido, se as 'situações', como se diz, correm riscos reais, o colonizador se sente então ameaçado e pensa, seriamente desta vez, em voltar para a metrópole".

Todos são dilemas que fazem parte do cotidiano da população, não daremos conta de aprofundarmos neste artigo, entretanto, a reflexão gerada por Graça responde a sua preferência em focar no ensaio sociológico, muito mais do que o fenômeno literário, pois o primeiro dá conta de explicar as contradições de subjugação do segundo. Segundo ele, a urgência se faz em compreender tamanhas contradições, de como uma terra tão rica pode ser, ao mesmo tempo, tão pobre, e conclui, consonante com Memmi (2007), que "a vida na região é decidida por interesses inteiramente alheios a ela" (GRAÇA; et. al.,1985, p. 43).

O segundo ensaio, feito por Aldísio Filgueiras ${ }^{10}$, intitulado Literatura e poder, avança a discussão da opressão, afirmando que todas as relações artísticas estão sempre imbricadas, de alguma forma, pelo poder. O complexo de culpa carregado por diversas gerações gerando um espírito 
conformista, revelaria o papel do colonizador na imposição cultural, desde o princípio mais preocupado em determinar sua língua do que criar universidades, por exemplo, pois a liberdade de pensar e se expressar esbarra nos interesses do dominante (SOUZA, 1978). "A língua portuguesa tem mais de 100 anos de dominação na Amazônia, como idioma e pensamentos oficiais" (FILGUEIRAS, et. al., 1985, p. 54). A afirmação confere que o discurso do colonizador sempre se fez presente, e pode ser exemplificado pelo poema A Muhraida, ou a conversão, e reconciliação do Gentio-Múhra, primeiro poema épico sobre a região, argumentado do ponto de vista do vencedor, por Henrique João Wilkens, em 1819. Segundo Memmi (2007), o lucro, o privilégio e a usurpação fazem parte da consciência do colonizador, acostumado a obter privilégios pela exposição de seu triunfo.

Para Filgueiras (1985), o pensamento colonizador e imperialista na contemporaneidade ganhou outras técnicas, como a ferramenta tecnológica, mediada pela televisão, e atualmente mais presente pela internet, tornando-se uma nova via de padronização da cultura, dos meios de produção, da ideia de progresso, visando também a homogeneização dos saberes e crenças. 0 autor traz a discussão para pensarmos no processo de subjugação do pensamento amazônico, resultando na falta de produção artística (discutido anteriormente), o que, segundo ele, explicaria - gaúcho Raul Bopp atravessar o país para reinventar a narrativa da Cobra Norato, 1931, e Mário de Andrade recriar a mitologia indígena brasileira no aclamado Macunaíma, de 1928. Essas implicações lançam olhar para o controle dos meios de produção, sempre nas mãos de uma pequena parcela, sequela de um sistema educacional alienante, reprodutor de um discurso "oficial". "Então, o processo de produção da ignorância, começa no $A B C$, se reproduz nos graus médios, e afinal desemboca num negócio indefinido chamado Universidade" (FILGUEIRAS, et al.,1985, p. 52).

A principal questão colocada pelo autor é como recuperar os saberes populares sob a ótica da construção do saber letrado. Nesse caso, a reflexão é convocada para os autores "de expressão amazônica" pensarem a sua ferramenta de combate por meio da linguagem. A linguagem seria a arma do poeta para "dessacralizar a realidade que os aparelhos do Estado tentam esconder desvirtuando o sentido do ensino" (Idem, p. 53), impedindo que o conhecimento chegue às classes trabalhadoras, impondo meios de alfabetização incoerentes com o saber empírico ${ }^{11}$, e ludibriando a população com soluções desenvolvimentistas.

Por fim, Filgueiras faz um apelo aos escritores amazônicos, para quebrar o silêncio sobre a região, que sempre se apresentou como verdadeiro mistério de tradução, mas que isso não impede o dever de tentá-la. 0 ensaio seguinte, Iracema e a Transa ideológica- cadê a identidade, de Narciso Lobo $^{12}$, faz um panorama a partir do filme de Jorge Bondanzky, Iracema uma transamazônica, concluído em 1975, e rodado com recursos da Televisão alemã. O filme, censurado por anos, contou apenas com dois atores profissionais, Paulo Cesar Pereio e Conceição Senna. A protagonista Edna de Cássia, na ocasião com 14 anos, nunca tinha assistido um filme.

Com o roteiro de Orlando Senna, o longa foi feito com diálogos improvisados, no objetivo de documentar o processo de construção das novas rodovias, como a BR-230, conhecida como Transamazônica ${ }^{13}$, e o processo de devastação provocado. A equipe percorreu treze mil quilômetros de Belém a Brasília, para armar o plano ficcional da prostituta Iracema, personagem titular. Lobo (1985) chama a atenção para o nome simbólico dado a personagem, pois Iracema é anagrama de América, e também título do romance indianista de José de Alencar, Iracema, de 1865. Outras coincidências são relatadas pelo autor, como a comparação musical de Caetano Veloso, entre Ipanema e Iracema.

O interessante é notar a paisagem como potencial narrador, fala por $\mathrm{si}_{\text {, }}$ descrevendo todo o contexto de um período. Vivia-se o ufanismo de desenvolvimento, do "Brasil Grande", presente no nome e no discurso do personagem "Tião Brasil Grande", e no jargão "Brasil, ame-o ou deixe-o", escrito no para-choque do seu caminhão. Assim, o caráter documental, ainda que costurado ao ficcional, ganha maior amplitude.

Lobo enxerga no filme uma possibilidade de discutir a ideia de identidade cultural contrapondo a obra fílmica com a obra literária de Alencar. Para isso, ele recorre ao aspecto histórico, em consonância com Graça e Filgueiras, para tratar de memória. A imposição dos colonizadores fez 
parte de um projeto de apagamento da memória, e, portanto, de identidade. "O índio é declarado "civilizado" ou "emancipado" quando lê e escreve em português e conta a história da colonização portuguesa, a história do dominador como se fosse a própria história" (LOBO; et. al., 1985, p. 63). Essa dinâmica é dolorosa, sobretudo, para os indígenas de diversas etnias que, ao chegarem na cidade, sofrem inúmeros preconceitos, e, por isso, se esforçam para apagar suas raízes. A recuperação do processo linguístico, tão bem posto por Filgueiras, trabalha nesse sentido, por isso muitas lideranças insistem em se comunicar no seu idioma de origem, como afirmação e resistência de sua identidade étnica, assim como vários projetos têm atuado na premissa de manutenção linguística.

Em se tratando da narrativa, a Iracema de Alencar, virgem dos lábios de mel em guarani, guarda a beleza e a pureza de sua ancestralidade, guarda o fruto proibido provedor de Jurema (bebida alucinógena), até ser desvirginada por Martín, o viajante aventureiro, gerando Moacir, o filho do sofrimento, aquele que representaria os povos mestiços. A propósito, no filme, Tião confunde o nome de Iracema por Jurema, aludindo ao romance. No filme, Iracema também possui o biotipo indígena, e passa a prostituirse para se sustentar. Figura ingênua, se afeiçoa a Tião, o anti-herói, que se aproveita dela como consequência do acaso. Essa Iracema representa a figura desmemoriada que passa pelo doloroso processo de destribalização. Em uma passagem, a jovem nega suas origens: "Não sou índia, sou brasileira", em resposta ao julgamento de Tião (LOBO, et al., 1985, p. 56).

Os dois se conhecem na ocasião dos festejos do Círio de Nazaré, em Belém, Iracema toma carona com Tião e envolve-se com ele durante a viagem. Em determinado momento, ele se cansa da jovem e a larga em um prostíbulo de estrada. Após uma passagem de tempo, um reencontro acontece, Iracema está na beira da estrada junto a outras prostitutas, quando aparece Tião, aparentemente melhor de vida, levando um carregamento que pretende atravessar a América (menção ao anagrama). Já a moça, está fisicamente maltratada por más condições, sem um dente, e sem perspectivas de futuro, à mercê da exploração.
O que nos interessa é ver como o mito proposto por Alencar se transforma no anti-mito, proposto por Lobo, que compara Iracema a população brasileira, "na situação de expropriada física e culturalmente" (LOBO, et al., 1985, p. 67). 0 autor propõe no ensaio um esquema das diferentes características entre Tião e Iracema, uma forma de traduzir sua representação simbólica. Tião Brasil Grande é: "discurso do poder, busca do dinheiro, penetrador, ativo, o que dirige, o que conduz, o que manda, o que retira a riqueza, o branco, o que sabe da lei, o que tem o capital..." (LOBO, et. al., 1985, p. 68). Iracema: "receptáculo, busca de sobrevivência, penetrada, passiva, a que é dirigida, a que é conduzida, a que obedece, a que empobrece, a indígena, a que não sabe, a que tem o corpo..." (LOBO, et al., 1985, p. 69). Assim, os planos e sequências do filme trabalham na chave da representação e do simbólico, muito mais documental do que ficcional, propondo um discurso que atinge outras camadas de interpretação, acentuado pela câmera. "Os ruídos, as músicas de amor e de exaltação da pátria, os diálogos, estão na tradição de um certo cinema documental" (LOBO, et al., 1985, p. 70), que traduzem o plano simbólico e icônico a que pretende.

Através do esquema, podemos relacionar Iracema como a própria representação da Amazônia, aquela que virou "puta", terra explorada pelo sistema colonial, imperialista e mais recente, capitalista. A Amazônia enquanto mulher é uma alegoria também utilizada na peça As Folias do Látex, 1976, de Márcio Souza, sua Amazônia começa moça virgem e inocente e termina vendida, iludida, de personalidade mudada aos interesses econômicos (SOUZA, 1984).

Lobo (1985) atualiza a contradição da região sob as lentes cinematográficas, num momento em que muitos diretores se voltaram para olhar a região, Cacá Diegues, Caldeira e o próprio Bodanzky novamente. As diversas leituras sobre a Amazônia, certamente permanecerão estimulando trabalhos artísticos que tentarão explicar seus impasses, ao que depender da comédia de erros da história do Amazonas, conforme examina Souza (1978). o anti-mito, argumentado na discussão, encontra no cinema documental, artifício necessário e eficaz para compor um painel de denúncia, sem abrir mão do valor estético. 
No terceiro ensaio, Bosco Ladislau ${ }^{14}$ fala da Pintura amazonense - contexto e manifestações artísticas, onde traça um panorama da história da pintura brasileira e seu desenvolvimento, marcado inicialmente pela pintura sacro religiosa, de imitação estrangeira e caráter autodidata; conseguinte, a pintura de retratos, à serviço da burguesia colonial, permanecendo na linha de inspiração estrangeira; em seguida a pintura romântica; e atualmente o convívio de diversas estéticas amparadas, sobretudo, nas escolas europeias:

É no âmbito das artes plásticas que o vanguardismo assume o papel preponderante. A pintura brasileira se, a partir de 1922, adotara a linguagem da pintura europeia, usara-a para captar de forma moderna a temática nacional, sem levar em conta a problemática básica daquela pintura que, na Europa, do mesmo modo que a literatura, se encaminharia para formas de expressão cada vez mais abstratas. A pintura brasileira, consequentemente, não sofreu essa evolução, cujos resultados - o concretismo de Bill, o abstracionismo da Escola de Paris e, mais tarde, o informalismo dos norte-americanos e europeus - seriam adotados pelas gerações do pósguerra. Contra essa onda formalista, esboçamse algumas reações, que irão se consolidar mais tarde, no setor da poesia e especialmente do teatro (GULLAR, 1978, p. 21).

São essas as condições apresentadas por Ladislau para iniciar a inserção da pintura no Amazonas. É dentro de um contexto de dependência, de dominação, passividade, e marginalização do mundo industrializado, que, contraditoriamente, surgem novas galerias, exposições individuais e tentativas coletivas, venda de objetos artísticos fora de seu ambiente comum, como shoppings, supermercados, bancas de jornais, etc., mediadas pelo mercado consumidor, trazendo à discussão o questionamento da relação do mundo da arte com o comercial, assunto espinhoso e amplamente debatido. É sobre essa era, a era da reprodutibilidade técnica que Benjamin ${ }^{15}$ (1955) afirmou que a obra de arte sempre foi reprodutível, e a tendência tecnicista de expandila cada vez mais em nome do capital, porém um fator é primordial para sua autenticidade, para a manutenção do que ele denomina de aura: o aqui e o agora. Para Benjamin, se essa obra perde sua aura, ela perde também toda a sua função social enquanto objeto artístico.

Mas, se essa abertura de espaços, com todas essas contradições, promoveu artistas e democratizou por um Iado, Ladislau afirma que no Amazonas funcionou diferente. Em outras partes do país isso era evidente, mas no Estado, eram incipientes, naquele momento, as condições de trabalho do artista plástico, sua formação e melhoria técnica, bem como os meios para expor seu trabalho. A falta de um mercado consumidor é outro fator que obrigou, e de certa forma ainda obrigada, os artistas a deixarem sua cidade natal para tentar outros meios. Ladislau critica as soluções oferecidas pela política paternalista do estado em troca do silenciamento e passividade do artista, tendo que lidar ainda com o chá de cadeira burocrático, e quando consegue algo, lida com o vexame de ser um favor e não uma ação de política pública:

Há um secreto alívio em Manaus quando morre um artista amazonense. Menos um para aporrinhar as ante-salas do Governo. Sobretudo se o desaparecido tenha se recusado a ser subserviente ou biscateiro e tenha insistido em viver na sua terra, preocupando-se com o seu povo e trabalhando com coisas de índios e caboclos (SOUZA, 1978, p. 19).

O caminho dos artistas, diante dessa situação, era trilhar o modismo das escolas europeias, especializando-se em alguma vanguarda: cubista, dadaísta, expressionista. O que, segundo ele, nada contribuiria para um debate amazônico. Em compensação, o segundo caminho:

[...] Possivelmente inferior ao primeiro, em relação a determinados conhecimentos, no campo da pintura, em contrapartida, estaremos diante de alguém que possui uma vontade criadora e que, por isso mesmo, é potencialmente capaz de caracterizar nossa pintura como original na medida em que se manifestam as legítimas expressões de nossa terra, do nosso povo, da nossa cultura, e do nosso tempo, tal como ele foi visto, compreendido e traduzido (LADISLAU, et al., 1985, p. 78).

Entretanto, os casos propensos corresponderiam ao primeiro exemplo. Ladislau analisa que a pintura contemporânea preserva maiores traços do academicismo, rememorando o passado colonial, tropeçando em um "regionalismo ora exótico, ora banal" (Idem). A saída para tal situação estaria na união dos artistas em busca de meios alternativos para os novos rumos da pintura, a partir da discussão do seu entorno. Aprofundar o estilo, perseverar contra as adversidades e desenvolver a capacidade criadora de olhar o entorno, seria a fórmula de Ladislau para uma "autêntica pintura amazonense", a 
união entre forma e conteúdo (1985, p. 79). A solução não está somente no plano do ideário, o artista se embasa em outros que despontaram nesse caminho. Entre eles: Manuel Santiago, de linha impressionista, um dos precursores da arte abstrata no Brasil, sem abandonar o toque de amazonidade, e Hahnemann Bacelar, jovem prodígio, garantiu seu espaço ao lado de grandes nomes, pintando em suas telas o cotidiano da vida cabocla. Além de artistas comprometidos, destacam-se equipamentos culturais que surgem na contramão burocrática, tornando-se alternativa de espaço artístico e de resistência.

O manifesto encerra alertando o avanço capitalista sobre a arte, tornando-a comercial, acrítica, a-histórica, ou seja, sem aura, na tentativa de que o artista perca o maior valor de sua obra, a sua liberdade. Diante disso, a necessidade de estar atento ao seu tempo, numa reflexão crítica constante, cabendo esta função ao artista plástico contemporâneo amazonense. Por fim, Dori Carvalho ${ }^{16}$ encerra o quinteto de ensaios, com "O teatro no Amazonas e eu", partindo de sua vivência de sete anos no movimento teatral manauara.

A reflexão inicia regressando ao passado, analisando as apresentações no glorioso monumento do Teatro Amazonas, onde basicamente se reproduziram as cópias das cópias ${ }^{17}$ (AZANCOTH e COSTA, 2014; CARVALHO, et al., 1985). Eram peças de fora que traziam temporadas desgastadas de outras regiões, e tentavam a sorte com as plateias amazonenses, reforçando uma lógica de padronização do espelho europeu, presente desde os tempos coloniais. "Os países adiantados eram, como disse Marx, o espelho das colônias. O Brasil via, nos países europeus, o seu futuro, para onde ele caminhava" (GULLAR, 1978, p. 17). Ou ainda, como diz o ditado popular "o melhor é sempre o que vem de fora".

Manaus, portanto, além de padecer pelo isolamento geográfico, o marasmo cultural e a falta de incentivos, permaneceu por muito tempo à sombra do que vinha de outras paragens ${ }^{18}$. Na década de 1970, mais precisamente em 1979, o autor presencia uma efervescência política e cultural que revelou outra dinâmica, possivelmente pela ditadura que demonstrava maior abertura. Um dos grupos que the chama atenção, embora não nomeie, é o Teatro Experimental do Sesc ${ }^{19}$ (TESC), não pelo viés popular, mas pelo seu trabalho de resistência constante que alcançou certo reconhecimento nacional, furando a bolha provinciana, e discutindo temas pertinente da região: o protagonismo das mitologias indígenas e um revisionismo crítico da história do Amazonas.

Outro grupo lembrado por Carvalho é o Grupo Universitário do Amazonas ${ }^{20}$, o Gruta, constituído por jovens universitários da área de filosofia, tinha como principal premissa levar o teatro ao povo por meio do teatro político, atuando principalmente nas periferias. Outros artistas e dramaturgos foram despontando, percebendo no cotidiano amazônico o estímulo para sua arte, como o caso do diretor e dramaturgo Francisco Carlos ${ }^{21}$.

Essa efervescência, à qual Carvalho se refere, tem a ver também com o surgimento de inúmeros grupos de bairros e fervilhar do movimento de teatro de bonecos, onde se destacaram artistas que permanecem na cena até hoje, como a diretora e atriz Socorro Andrade, diretora da Companhia de Teatro Metamorfose, ainda atuante. Mas, o que sugeria soprar novos rumos, acabou pelo esvaziamento de desses movimentos, restando poucos resistentes diante das dificuldades de sempre:

É aquela velha história: a política cultural intimamente ligada à política econômica - um povo massacrado, que passa fome, com salários indignos, com moradias indignas, ensino decrépito e com sua identidade roubada é óbvio que não se interessa nem pode ir ao teatro (CARVALHO, et al., 1985, p. 87).

Carvalho resume nestas linhas todos os percalços descritos pelos outros artistas ao longo dos ensaios, lançando uma grande questão: como culpar a falta de público e produções se não há constância. E não há constância porque não há o básico, o investimento na educação e no bem comum. Entre todas as análises presentes, vimos a insistência na atuação de um teatro popular, mas Carvalho ressalta que, no caso do teatro, eram todos amadores, ou seja, sem condições mínimas para exercer essas incursões, preocupados primeiro com o auto sustento e de suas famílias, com a manutenção dos empregos, etc., e por último vinha a preocupação artística, resumindo tudo o que impede um teatro de se desenvolver.

Por isso, as políticas públicas se fazem tão necessárias, pois não se trata de uma assistência paternalista e sim de "fomentar e distribuir a 
produção", mas, que só se concretizará se houver união da classe artística enquanto organização, para fazer pressão aos setores culturais (CARVALHO, et al., 1985, p. 88).

\section{Considerações finais}

Como visto, todos os ensaios flertam com questões sociológicas porque seus autores entendem que a arte nasce de uma profunda dependência relacional de conjunturas que a permeiam, em diversos aspectos: histórico, político, social, cultural, econômico, espacial e linguístico. Para obter as lentes dessa operação, o artista contemporâneo precisa conhecer sua história, seu entorno, seu contexto de dependência, e, por isso, o livro tem o tom de manifesto, pois tratase do grito da juventude amazônica oitentista, esperançosa pelos novos rumos que chegavam com a abertura democrática.

Nos resta, enquanto leitores contemporâneos, perceber as mudanças de lá para cá, ou mesmo as que permanecem. Dentro de todas as implicações possíveis:qual o espaço artístico nos novostempos? Como a classe artística tem operado diante das políticas culturais do Estado? Como o público tem consumido arte na cidade? Dentre tantas outras questões que a leitura tende a nos impulsionar, que mesmo se tratando de Manaus, dialoga com questões de esfera universal. Contudo, se trata aqui de manifestar um novo grito, de que a arte resistirá, ultrapassando todos os limites possíveis, readaptando-se criativamente aos mais diversos contextos, e isso depende, exclusivamente, do artista contemporâneo.

\section{NOTAS}

01. Sobre isso ver mais em Seminários - 0 Nacional e o Popular na Cultura Brasileira, de Marilena Chauí (1983).

02. Ato institucional número cinco. Medida de concentração de plenos poderes ao general presidente.

03. Não por acaso, encontra-se uma citação na apresentação "Soou a hora derradeira do artista individual, do gênio solitário, do acumulador inútil de erudição. Não mais a apropriação privada da cultura. $O$ criador da nova arte e literatura popular é uma usina humana multiplicador de ações.
As grandes obras são os grandes movimentos" (NAÇÃO CARIRI apud GRAÇA, et al., 1985, p. 27).

04. Mesmo assim, Amaral (2015) afirma que haviam membros da academia que apoiavam a ação dos jovens, como Djalma Batista.

05. Antônio Paulo Graça (1952-1998), nascido no município de Boca do Acre, no Amazonas, exerceu a função de ensaísta, teatrólogo, compositor e crítico literário, e com formação de Mestre e Doutor em Teoria da Literatura. "Escreveu para jornais de Manaus e para o Jornal do Brasil no Rio de Janeiro, dedicou-se à análise do fenômeno literário, oferecendo oportunos estudos sobre autores estrangeiros e brasileiros, inclusive amazonenses, dinamizando e valorizando a crítica literária" Escola Paulo Graça. Disponível em: < http://escolapaulograca.blogspot. com/2012/07/nossa-escola.html>. Acesso em: 28 de maio de 2020 .

06. Projeto de lei criado em 1957, mas executado apenas em 1967. Significou um grande passo rumo à integração da região amazônica à expansão capitalista nacional, arquitetado pelo regime militar visando à soberania nacional sobre a Amazônia. Foi criado o Distrito Industrial de Manaus (em crescimento constante) para abrigar as inúmeras fábricas estrangeiras, que possuem diversas vantagens concedidas, desde terrenos a preços simbólicos a taxas de imposto irrisórias.

07. Termo discutido por Walter Benjamin, nas Teses sobre o conceito de história (1940).

08. O discurso da Superintendência da Zona Franca (SUFRAMA), é de que a Zona Franca é responsável pela maior parte da preservação florestal da região, embasada por estudos enviesados, conforme aponta Sakamoto, pois desconsidera os povos originários e o processo infraestrutural que opera nestas áreas. Ver mais em: < https://blogdosakamoto.blogosfera.uol. com.br/2019/04/30/zona-franca-de-manausame-a-ou-deixe-a-em-nome-da-floresta/>. Acesso em: 28 de maio de 2020.

09. O texto original foi publicado em 1973. A versão aqui utilizada é a Versão digitalizada conforme publicado em "Ruy Mauro Marini: Vida e Obra", Editora Expressão Popular, 2005. Orgs. Roberta Traspadini e João Pedro Stedile. Este documento 
encontra $\rightarrow-$ se em< www.centrovictormeyer.org. br>. Acesso em: 25 de maio de 2020.

10. É poeta, compositor e jornalista, nascido em Manaus em 1947. Publicou o livro de poemas Estado de Sítio, em 1968, além de Malária e outras canções malignas (1976); A República muda (1989); Manaus - as muitas cidades: 1987-1993 (1994); A dança dos fantasmas (2001) e Nova subúrbios (2004), são alguns dos títulos do autor.

11. A MOBRAL foi um exemplo. O Movimento Brasileiro de Alfabetização, criado pelo Regime Militar e efetivado em 1970, foi um mecanismo de substituição impositiva aos movimentos de alfabetização pelos métodos de Paulo Freire. O movimento pretendia erradicar o analfabetismo, mas na prática teve pouco eficácia. Ver mais em: <http:// www.fgv.br/cpdoc/acervo/dicionarios/verbetetematico/movimento-brasileiro-de-alfabetizacaomobral>. Acesso em 28 de maio de 2020.

12. Foi docente do curso de Comunicação Social, do Programa de Pós-Graduação em Sociedade e Cultura na Amazônia e do Programa de PósGraduação em Comunicação da Universidade Federal do Amazonas (UFAM). Foi chefe do Departamento de Comunicação Social, próreitor de Assuntos Comunitários e presidente da Associação dos Docentes da Universidade Federal do Amazonas (ADUA). Era membro da Academia Amazonense de Letras, militante, jornalista e grande representante dos estudos de cinema.

13. Projeto faraônico do Governo Militar, foi construída entre os anos de 1969-1974, com o objetivo de integrar a região Norte ao restante do país.

14. Engenheiro civil, poeta, escritor e artista plástico. É professor da Universidade Federal do Amazonas.

15. 1955 é referente ao primeiro ano de sua publicação. Utilizamos aqui a edição Magia e Técnica, Arte e Política. $3^{\circ}$ ed. São Paulo: Brasiliense, 1987.

16. Amazonense de São Joaquim da Barra (SP), nascido em 1955, Dori ganhou o título de cidadão amazonense pela Assembleia Legislativa do Amazonas em 2019. É ator, diretor, Poeta, promotor cultural, apresentador... Publicou Desencontro das águas, em 1987, Paixão e fúria, 2004 e Meu ovo esquerdo, 2012.
17. O artista se refere as produções sulistas que também copiavam o modelo Broadway, gerando uma cópia. Por muito tempo, companhias amazonenses reproduziram o fazer artístico sulista, tornando-se, por sua vez "a cópia da cópia".

18. Azancoth e Costa (2014) registram o painel teatral do Amazonas em mais detalhes, mas podemos destacar que em meados da década de 1960, ocorrem as primeiras mudanças de repertório.

19. O grupo surgiu em 1968, e permaneceu até 2016, amparado pelo Serviço Social do Comércio do Amazonas. Passou por diversas fases e formações, e teve como principais diretores Nielson Menão e Márcio Souza. Ver mais em TESC - nos bastidores da lenda, de Selva Vale e Ediney Azancoth (2009).

20. Criado em 1973, no Conservatório de Música da Universidade do Amazonas (UA), o Gruta atuou com um teatro engajado até 1991. Também passou por diversas formações e teve como seus principais condutores Marcos José e Rui Brito.

21. Nasceu em Itaquatiara, Amazonas, em 1960, e desde 2005, mora em São Paulo. É formado em Filosofia na Universidade do Amazonas, e denomina o seu teatro como "poético-míticofilosófico-etnográfico", transitando entre linguagens artísticas.

\section{REFERÊNCIAS}

AMARAL, Vinícius. Como cansa ser artista nos trópicos: intelectuais e política cultural no amazonas (1964-1968). Anais do XXVIII Simpósio Nacional de História, Florianópolis, Santa Catarina, 2015.

AZANCOTH, Ediney; COSTA, Selda Vale da. Amazônia em cena: Grupos teatrais em Manaus (1969-2000). Manaus: Editora Valer, 2014.

BENJAMIN, Walter. "A obra de arte na era de sua reprodutibilidade técnica". In: Magia e Técnica, Arte e Política. $3^{\circ}$ ed. São Paulo: Brasiliense, 1987.

BOAL, Augusto. Que pensa você da arte de esquerda? In: I Feira Paulista de Opinião. São Paulo. Expressão Popular, 2016. 
CAMARGO, Iná. A hora do teatro épico no Brasil. Rio de Janeiro: Paz e Terra, 1996.

CUNHA, Luís Antônio. Cunha; Xavier, Libânia. Movimento brasileiro de alfabetização (Mobral). Disponível em: <http://www.fgv.br/ cpdoc/acervo/dicionarios/verbete-tematico/ movimento-brasileiro-de-alfabetizacaomobral>. Acesso em 28 de maio de 2020.

GRAÇA, Antônio Paulo et. al. Arte e delírio reflexões sobre a cultura no Amazonas. Manaus: Diretório Universitário da Universidade do Amazonas, 1985.

GULLAR, Ferreira. Vanguardas e subdesenvolvimento. $2^{\circ}$ edição, Civilização brasileira, Rio de Janeiro, 1978.

MARINI, Rui Mauro. Dialética da dependência. 1973. Germinal: Marxismo e Educação em Debate, Salvador, v. 9, n. 3, p. 325-356, dez. 2017.

MEMMI, Albert. Retrato do colonizado precedido do retrato do colonizador. Rio de Janeiro: Civilização Brasileira, 2007.

SAKAMOTO, Leonardo. Zona Franca de Manaus, ame-a ou deixe-a (em nome da floresta), 2019. Disponível em: <https://blogdosakamoto. blogosfera.uol.com.br/2019/04/30/zona-francade-manaus-ame-a-ou-deixe-a-em-nome-dafloresta/>. Acesso em: 28 de maio de 2020.

SCHWARZ, Roberto. "Cultura e política, 19641969". In: O pai de família e outros estudos. Rio de janeiro: Paz e Terra, 1978.

SOUZA, Márcio. A Expressão Amazonense: Do colonialismo ao neocolonialismo. São Paulo: Alfa Ômega, 1978.

SoUZA, Márcio. o Palco Verde. Rio Comprido: Marco Zero, 1984.

TUFIC, Jorge. Clube da Madrugada: 30 anos. Manaus: Imprensa Oficial, 1984.

RIDENTI, Marcelo. Brasilidade revolucionária: um século de cultura e política. São Paulo: Editora UNESP, 2010.

PETILLO. Cleider Baima. Nossa Escola. Disponível em: <http://escolapaulograca.blogspot. com/2012/07/nossa-escola.html>. Acesso em: 28 de maio de 2020 .

\section{SOBRE O AUTOR}

Howardinne Queiroz Leão é bacharel em teatro, com ênfase em interpretação e direção pela Universidade do Estado do Amazonas-UEA (2014); especialista em direção teatral pela Escola Superior de Artes Célia Helena (2016), aprendiz de direção teatral pela SP Escola de Teatro (2018) e mestranda do programa de Artes Cênicas da USP na linha de pesquisa de História do teatro brasileiro com bolsa CAPES PROEX código 001. Em Manaus integrou diversas companhias e ministrou aulas de teatro em escolas e cursos livres de Manaus. Foi contemplada com o prêmio PROARTE- Programa de Apoio às Artes (2013), pela Secretaria do Estado de Cultura do Amazonas, com bolsa apoio de Pós graduação em Direção Teatral - Escola Superior de Artes Célia Helena-2016, São Paulo. Posteriormente integrou o núcleo de estudos Anatol Rosenfeld da Cia. do Latão (2015); atuou como educadora sociocultural na ONG Vocação (2015) e como oficineira de teatro no CAPS Infantil (2016). Ganhou o concurso para integrar a II Mostra de Teatro do ônibus realizado pela ZózimaTrupe, como diretora do espetáculo "Saída Discreta pela porta dos fundos", do grupo homônimo. Participou de diversas oficinas e cursos de formação teatral. Foi atriz na série audiovisual BOTO da Artrupe produções artísticas, contemplado pelo edital de TVs públicas da ANCINE; co-dirige o espetáculo "Em carne viva", do Coletivo Encarnadas (São Paulo) contemplado pelo edital VAI 2017. Integra os grupos: Núcleo de diretores e Nosotros coletivo, onde atua e dirige. Ganhou o prêmio de intercâmbio da Secretaria de Cultura para estudar técnicas de Meisner na Escola Internacional de Cinema e TV em San António de los baños, Cuba, no ano de 2020. 